\title{
Effects of Heat Stress on Gut-Microbial Metabolites, Gastrointestinal Peptides, Glycolipid Metabolism, and Performance of Broilers
}

\author{
Guangju Wang, Xiumei Li, Ying Zhou, Jinghai Feng and Minhong Zhang * \\ State Key Laboratory of Animal Nutrition, Institute of Animal Sciences, Chinese Academy of Agricultural \\ Sciences, Beijing 100193, China; 82101185163@caas.cn (G.W.); 1lxiumei93@163.com (X.L.); \\ 15624955881@163.com (Y.Z.); fjh6289@126.com (J.F.) \\ * Correspondence: zmh66@126.com; Tel.: +86-10-6289-5517
}

check for updates

Citation: Wang, G.; Li, X.; Zhou, Y.; Feng, J.; Zhang, M. Effects of Heat Stress on Gut-Microbial Metabolites, Gastrointestinal Peptides, Glycolipid Metabolism, and Performance of Broilers. Animals 2021, 11, 1286. https://doi.org/10.3390/ani11051286

Academic Editor: Natalie Morgan

Received: 31 March 2021

Accepted: 28 April 2021

Published: 30 April 2021

Publisher's Note: MDPI stays neutral with regard to jurisdictional claims in published maps and institutional affiliations.

Copyright: (C) 2021 by the authors. Licensee MDPI, Basel, Switzerland. This article is an open access article distributed under the terms and conditions of the Creative Commons Attribution (CC BY) license (https:/ / creativecommons.org/licenses/by/ $4.0 /)$.
Simple Summary: In the summer, heat stress is a main factor that causes poor performance in broilers. Broilers are more susceptible to high temperature environments than mammals due to their lack of sweat glands and being covered in feathers. Heat stress can alter the regulation of glycolipid metabolism, which is manifested by unstable levels of blood glucose, insulin, total cholesterol, and triglyceride. Heat stress also affects the structure of gut microbes and gastrointestinal peptides. However, the relationship among microbiota, gastrointestinal peptides, glycolipid metabolism, and production performance under heat stress is still unclear. Moreover, exploring these mechanisms can help in the development of strategies that alleviate the negative effects of performance by heat stress. Our results suggest that the poor production performance of broilers under heat stress may be related to short chain fatty acids fermented by intestinal microbiota involved in regulating metabolic disorders.

Abstract: This paper investigated the effects of heat stress on gut-microbial metabolites, gastrointestinal peptides, glycolipid metabolism, and performance of broilers. Thus, 132 male Arbor Acres broilers, 28-days-old, were randomly distributed to undergo two treatments: thermoneutral control $\left(\mathrm{TC}, 21^{\circ} \mathrm{C}\right.$ ) and high temperature $\left(\mathrm{HT}, 31^{\circ} \mathrm{C}\right)$. The results showed that the average daily gain (ADG), average daily feed intake (ADFI), and gastric inhibitory polypeptide (GIP) concentration in the jejunum significantly decreased the core temperature, feed conversion ratio (FCR), and ghrelin of the hypothalamus, and cholecystokinin (CCK) in jejunum, and serum significantly increased in the HT group $(p<0.05)$. Exploration of the structure of cecal microbes was accomplished by sequencing $16 \mathrm{~S}$ rRNA genes. The sequencing results showed that the proportion of Christensenellaceae and Lachnospiraceae decreased significantly whereas the proportion of Peptococcaceae increased at the family level $(p<0.05)$. Ruminococcus and Clostridium abundances significantly increased at the genus level. Furthermore, the content of acetate in the HT group significantly increased. Biochemical parameters showed that the blood glucose concentration of the HT group significantly decreased, and the TG (serum triglycerides), TC (total cholesterol), insulin concentration, and the insulin resistance index significantly increased. Nonesterified fatty acid (NEFA) in the HT group decreased significantly. In conclusion, the results of this paper suggest that the poor production performance of broilers under heat stress may be related to short-chain fatty acids (SCFAs) fermented by intestinal microbiota involved in regulating metabolic disorders.

Keywords: heat stress; microbial metabolites; gastrointestinal peptides; glycolipid metabolism

\section{Introduction}

Chicken meat is considered an important source of dietary protein worldwide. As per the Food and Agriculture Organization (FAO), total global chicken production was 118.0 million tons in 2019 , accounting for a large proportion of the whole meat production. 
Broilers are severely affected by heat stress; it can cause slow growth rate, low feed intake, and decreased immunity, leading to economic losses [1,2]. Studies have shown that heat stress leads to glucolipid metabolism disorder [3-5]. Heat stress accelerates decomposition of glycogen and inhibits glycogen production [6]. When ambient temperature is higher than the tolerable limit of broilers, the energy produced cannot meet the needs, resulting in insulin resistance and glucolipid metabolism disorders [7]. Previous studies investigated the impacts of heat stress on broilers, which was found to cause blood glucose instability [3,8,9], decrease insulin sensitivity [10], serum cholesterol, and triglycerides [11], increase body fat in the abdomen, and decrease plasma non-esterified fatty acid (NEFA) concentrations [12]. Recently, several studies have shown that heat stress affects the metabolites and structures of the intestinal microflora $[13,14]$ and gastrointestinal peptide [15] in broilers. However, to date, there are no specific studies on the effects of heat stress on broiler microflora and its metabolites, gastrointestinal peptide, glycolipid metabolism, and the association among the three.

Multiple studies were conducted on the associations among bacterial metabolites, gastrointestinal peptides, and glucose and lipid metabolism on metabolic disorders in mice and humans. Intestinal microbiota are involved in metabolic processes and energy homeostasis [16]. Previous studies have shown that heat stress can alter the gut microbiota of mice [17]. The Firmicutes to Bacteroidetes ratio decreased significantly under $30^{\circ} \mathrm{C}$ [18]. Short-chain fatty acids (SCFAs) are metabolites formed by gut microbes from complex dietary carbohydrates. Researchers found that SCFAs stimulated mouse L cells to produce glucagon-like peptide 1 (GLP-1), peptide YY (PYY), and other intestinal anorexia hormones, reducing appetite [19]. GLP-1 and GIP are related to insulin secretion, and approximately $70 \%$ of $\beta$-cell insulin secretion is controlled by GIP and GLP-1 [20]. Insulin secretion disorders lead to metabolic disorders, such as diabetes and obesity [21]. As mentioned above, heat stress causes metabolic disorders in broilers. However, the association between metabolic disorder and microbiota under heat stress is still unclear in mice and humans.

Thus, the purpose of this study was to investigate the effects of heat stress on the microbiota and its metabolites, gastrointestinal peptides, and glycolipid metabolism in broilers, and explore the relationship among them to provide a scientific basis for reconstructing the intestinal flora, to alleviate the decline in production performance caused by heat stress.

\section{Materials and Methods}

\subsection{Animals and Experimental Design}

A total 132 male, one day old, Arbor Acres broilers were purchased from commercial hatcheries and housed in three-layer $\left(8400 \mathrm{~cm}^{2}\right.$ per layer) metal cages at ambient temperatures that decreased with age. All birds had free access to feed and water (room temperature) ad libitum. The broilers were fed on crumble diets (Table 1). Then, birds were divided into a thermoneutral control group $\left(\mathrm{TC}, 21^{\circ} \mathrm{C}\right)$ or a high temperature group (HT, $31^{\circ} \mathrm{C}$ ), with six biological replicates per group, 11 birds per replicate, at 21 days old. Birds were transferred to the environmental temperature control chamber, while maintaining a temperature of $21^{\circ} \mathrm{C}$, a humidity of $60 \%$, for 7 days. The experiment started at 28 days old. Temperature control was adjusted by an artificial environmental control chamber developed by the Institute of Animal Science of the Chinese Academy of Agricultural Sciences (CAAS). There was no significant difference in the initial body weight of broilers in the two groups. The temperature of the two groups was constant and humidity remained at $60 \%$ until the end of the experiment, which lasted for 21 days. The lighting program was continuous throughout the experimental (fluorescent light, $40 \mathrm{~W}$ ). To reduce stress, irrelevant personnel were prohibited from entering the artificial environment control chamber. This program was approved by the Experiment Animal Welfare and Ethical at the Institute of Animal Science of CAAS. 
Table 1. Composition and nutrient levels of the basal diet.

\begin{tabular}{cc}
\hline Items & Content (\%) \\
\hline Ingredients & \\
Corn & 56.51 \\
Soybean meal & 35.52 \\
Soybean oil & 4.50 \\
Na Cl & 0.30 \\
Limestone & 1.00 \\
Ca HPO & 1.78 \\
d L-Met & 0.11 \\
Premix (1) & 0.28 \\
Total & 100.00 \\
Nutrient levels (2) & \\
ME/(MJ/Kg) & 12.73 \\
CP & 20.07 \\
Ca & 0.90 \\
AP & 0.40 \\
Lys & 1.00 \\
Met & 0.42 \\
Met + Cys & 0.78 \\
\hline
\end{tabular}

(1) Premix provided the following per kg of the diet: VA 10,000 IU, VD3 $3400 \mathrm{IU}, \mathrm{VE} 16 \mathrm{IU}, \mathrm{VK} 32.0 \mathrm{mg}$ VB1 $2.0 \mathrm{mg}$, VB2 $6.4 \mathrm{mg}$, VB6 $2.0 \mathrm{mg}$, VB12 $0.012 \mathrm{mg}$, pantothenic acid calcium $10 \mathrm{mg}$, nicotinic acid $26 \mathrm{mg}$, folic acid $1 \mathrm{mg}$, biotin $0.1 \mathrm{mg}$, choline $500 \mathrm{mg}, \mathrm{Zn}\left(\mathrm{ZnSO}_{4} \cdot 7 \mathrm{H}_{2} \mathrm{O}\right) 40 \mathrm{mg}, \mathrm{Fe}\left(\mathrm{FeSO}_{4} \cdot 7 \mathrm{H}_{2} \mathrm{O}\right) 80 \mathrm{mg}, \mathrm{Cu}\left(\mathrm{CuSO}_{4} \cdot 5 \mathrm{H}_{2} \mathrm{O}\right)$ $8 \mathrm{mg}, \mathrm{Mn}\left(\mathrm{MnSO}_{4} \cdot \mathrm{H}_{2} \mathrm{O}\right) 80 \mathrm{mg}$, I(KI) $0.35 \mathrm{mg}, \mathrm{Se}\left(\mathrm{Na}_{2} \mathrm{SeO}_{3}\right) 0.15 \mathrm{mg}$. (2) Calculated values.

\subsection{Sample and Data Collection}

During the experiment, we used an $0.01 \mathrm{~g}$ sensitive electronic body weight scale (manufacturer: Mettler Toledo, PL2002) to record the initial feed weight, final feed weight, and body weight of the bird replicates, then calculated the average feed intake, average body weight, average daily weight gain, and feed efficiency for each replicate. This experiment used a rectal probe thermometer to measure the body core temperature of one bird replicate, which was randomly selected from each replicate, and measured four times a day during the experiment. At the end of the experiment, one bird, after $12 \mathrm{~h}$ fasting, was randomly selected from each replicate for insulin and blood glucose determination. Feed then continued for two hours, and one bird was randomly selected from each replicate to collect samples. The blood was immediately collected through the wing vein into heparinized tubes and centrifuged at $10,000 \times \mathrm{g}$ for $4 \mathrm{~min}$ at $4{ }^{\circ} \mathrm{C}$. Then the plasma was collected and stored at $-20^{\circ} \mathrm{C}$ until the analysis of the concentrations of PYY, ghrelin, CCK, GIP, and GLP-1. Immediately after the blood samples were obtained, the birds were humanely sacrificed, and the tissues of the cecum contents, intestinal mucosa, pancreas, and hypothalamus were collected. The samples were placed in a cryopreservation tube and stored in a $-80{ }^{\circ} \mathrm{C}$ refrigerator.

\subsection{Determination of Gastrointestinal Peptides}

The concentrations of CCK, Ghrelin, GLP-1, GIP, and PYY in the intestinal mucosa and serum were determined by the enzyme-linked immunosorbent assay (ELISA). The intestinal mucosa needed to be grinded, weighed, diluted with PBS buffer at 1:9, and centrifuged for $20 \mathrm{~min}$ (2000-3000 rpm). The supernatant was then carefully taken for testing. The standard wells were set up, the samples added (diluent and enzyme label reagent in sequence), and were incubated for $60 \mathrm{~min}$. The ELISA plate was washed with a washing solution for more than five times, and the color reagent and stop solution were added. Finally, an enzyme-labeled instrument was used to measure the absorbance of each well (OD value). The contents of each peptide in the sample were calculated through the standard curve. 


\subsection{DNA Extraction and PCR Amplification}

Microbial community genomic DNA was extracted from cecal content samples using the E.Z.N.A. ${ }^{\circledR}$ soil DNA Kit (Omega BioTek, Norcross, GA, USA) according to the manufacturer's instructions. The DNA extract was checked on $1 \%$ agarose gel, and DNA concentration and purity were determined with NanoDrop 2000 UV-vis spectrophotometer (Thermo Scientific, Wilmington, DE, USA). The hypervariable region V3-V4 of the bacterial $16 \mathrm{~S}$ rRNA gene was amplified with primer pairs $338 \mathrm{~F}$ ( $5^{\prime}$-ACTCCTACGGGAGG-CAGCAG$\left.3^{\prime}\right)$ and 806R (5'-GGACTACHVGGGTWTCTAAT $\left.-3^{\prime}\right)$ by an ABI GeneAmp ${ }^{\circledR} 9700$ PCR thermocycler (Applied Biosystems, Carlsbad, CA, USA). The PCR amplification of $16 \mathrm{~S}$ rRNA gene was performed as follows: initial denaturation at $95{ }^{\circ} \mathrm{C}$ for $3 \mathrm{~min}$, followed by 27 cycles of denaturing at $95^{\circ} \mathrm{C}$ for $30 \mathrm{~s}$, annealing at $55^{\circ} \mathrm{C}$ for $30 \mathrm{~s}$ and extension at $72{ }^{\circ} \mathrm{C}$ for $45 \mathrm{~s}$, and single extension at $72{ }^{\circ} \mathrm{C}$ for $10 \mathrm{~min}$, and end at $10^{\circ} \mathrm{C}$. The PCR mixtures contain $5 \times$ TransStart FastPfu buffer $4 \mu \mathrm{L}, 2.5 \mathrm{mM}$ dNTPs $2 \mu \mathrm{L}$, forward primer $(5 \mu \mathrm{M})$ $0.8 \mu \mathrm{L}$, reverse primer $(5 \mu \mathrm{M}) 0.8 \mu \mathrm{L}$, TransStart FastPfu DNA Polymerase $0.4 \mu \mathrm{L}$, template DNA $10 \mathrm{ng}$, and finally ddH2O up to $20 \mu \mathrm{L}$. PCR reactions were performed in triplicate. The PCR product was extracted from $2 \%$ agarose gel and purified using the AxyPrep DNA Gel Extraction Kit (Axygen Biosciences, Union City, CA, USA), according to manufacturer's instructions, and quantified using Quantus ${ }^{\mathrm{TM}}$ Fluorometer (Promega, Madison, WI, USA).

\subsection{Illumina MiSeq Sequencing}

Purified amplicons were pooled in equimolar and paired-end sequences on an Illumina MiSeq PE300 platform/NovaSeq PE250 platform (Illumina, San Diego, CA, USA), according to the standard protocols by Majorbio Bio-Pharm Technology Co. Ltd. (Shanghai, China).

\subsection{Processing of Sequencing Data}

The raw $16 \mathrm{~S}$ rRNA gene sequencing reads were demultiplexed, quality-filtered by fastp version 0.20.0 [22] and merged by FLASH version 1.2.7 [23] with the following criteria: (i) the $300 \mathrm{bp}$ reads were truncated at any site receiving an average quality score of $<20$ over a 50 bp sliding window, and the truncated reads shorter than $50 \mathrm{bp}$ were discarded. Reads containing ambiguous characters were also discarded. (ii) Only overlapping sequences longer than $10 \mathrm{bp}$ were assembled according to their overlapped sequences. The maximum mismatch ratio of overlap region was 0.2. Reads that could not be assembled were discarded. (iii) Samples were distinguished according to the barcode and primers, and the sequence direction was adjusted, exact barcode matched, and two nucleotides mismatched in the primer matching. Operational taxonomic units (OTUs) with $97 \%$ similarity cutoff [24,25] were clustered using UPARSE version 7.1 [24], and chimeric sequences were identified and removed. The taxonomy of each OTU representative sequence was analyzed by RDP Classifier version 2.2 [26] against the $16 \mathrm{~S}$ rRNA database using confidence threshold of 0.7 .

\subsection{Determination of SCFAs}

We accurately weighed $1 \mathrm{~g}$ of cecal content, added $5 \mathrm{~mL}$ of ultra-pure water, shook, and mixed for $30 \mathrm{~min}$, overnight at $4{ }^{\circ} \mathrm{C}$, then centrifuged at $10,000 \mathrm{rpm}$ for $10 \mathrm{~min}$, and transferred the supernatant to a $10 \mathrm{~mL}$ cuvette. We added $4 \mathrm{~mL}$ of ultra-pure water to the precipitation, shook and mixed for $30 \mathrm{~min}$, then centrifuged at 10,000 rpm to transfer the supernatant into a $10 \mathrm{~mL}$ cuvette for constant volume. We transferred the liquid in the colorimetric tube to a $10 \mathrm{~mL}$ centrifuge tube, centrifuged at $12,000 \mathrm{rpm}$ for $15 \mathrm{~min}$, and then transferred the supernatant to a $2 \mathrm{~mL}$ centrifuge tube, according to $\mathrm{V}: \mathrm{V}=9: 1$ (900 $\mu \mathrm{L}$ supernatant $+100 \mu \mathrm{L} 25 \%$ metaphosphoric acid), mixed well, and let it stand at room temperature for 3-4 h centrifugation, $45 \mathrm{um}$ microporous membrane (nylon series) filtration. We added the machine bottle (more than $600 \mu \mathrm{L}$ ) to be tested. Chromatographic conditions: db-ffap column, $30 \mathrm{~m} * 250 \mu \mathrm{m} * 0.25 \mu \mathrm{m}$; carrier gas: high purity nitrogen (99.999\%), flow rate: $0.8 \mathrm{~mL} / \mathrm{min}$; auxiliary gas: high purity hydrogen $(99.999 \%)$, detector FID temperature: $280{ }^{\circ} \mathrm{C}$, injection port temperature: $250{ }^{\circ} \mathrm{C}$, split ratio: $50: 1$, injection 
volume: $1 \mu \mathrm{L}$; temperature programming: initial temperature: $60^{\circ} \mathrm{C}$, the temperature rose to $220^{\circ} \mathrm{C}$ at the rate of $20^{\circ} \mathrm{C} / \mathrm{min}$, and held for $1 \mathrm{~min}$.

\subsection{Determination of Serum Biochemical Parameters}

The concentrations of blood glucose, serum insulin, triglycerides, total cholesterol, and NEFA were measured using the kits provided by Nanjing Jiancheng Bioengineering Institute (Jiangsu, China). The insulin resistance index was calculated using a formula as previously described: insulin resistance index $=$ insulin $/\left(22.5 \mathrm{e}^{- \text {lnglucose }}\right)$ [27].

\subsection{Statistical Analysis}

All statistical analyses were conducted using GraphPad Prism 8 software (GraphPad Software, Inc. La Jolla, CA, USA). An independent sample t-test (unpaired Student's $t$ test and Mann-Whitney test) was used for the comparison of the two treatments. Replicate served as the experimental unit. The confidence interval was $95 \%$, and $p<0.05$ indicated a significant difference in the treatment effect; values were expressed as the mean $\pm \mathrm{SEM}$.

\section{Results}

\subsection{Effect of High Temperature on Performance}

The effect of heat stress on performance is shown in Table 2. Compared with the TC group, ADG and ADFI in the HT group decreased significantly $(p<0.05)$. Compared with the TC group, the core temperature of birds and FCR in the HT group significantly increased $(p<0.05)$.

Table 2. Effects of thermal environment on performance indices of broilers during experiment period.

\begin{tabular}{ccccc}
\hline \multicolumn{2}{c}{ Treatments } & & \\
\hline Item & TC & HT & SEM & $p$ Value \\
\hline IABW $(\mathrm{g})$ & 1427.31 & 1432.10 & 19.35 & $>0.05$ \\
\hline FABW $(\mathrm{g})$ & $2840.22^{\mathrm{a}}$ & $2567.78^{\mathrm{b}}$ & 24.32 & $<0.05$ \\
\hline ADG $(\mathrm{g} / \mathrm{d})$ & $80.58^{\mathrm{a}}$ & $70.70^{\mathrm{b}}$ & 5.03 & $<0.05$ \\
\hline ADFI $(\mathrm{g} / \mathrm{d})$ & $157.51^{\mathrm{a}}$ & $148.95^{\mathrm{b}}$ & 7.16 & $<0.05$ \\
\hline FCR $(\mathrm{g} / \mathrm{g})$ & $1.95^{\mathrm{b}}$ & $2.11 \mathrm{~b}^{\mathrm{a}}$ & 0.11 & $<0.05$ \\
\hline CT $\left({ }^{\circ} \mathrm{C}\right)$ & $41.49^{\mathrm{b}}$ & $42.66^{\mathrm{a}}$ & 1.28 & $<0.05$ \\
\hline
\end{tabular}

Values are means \pm SEM. TC, thermoneutral control group; HT, high temperature group; IABW, initial average body weight ( $29 \mathrm{~d})$; FABW, final average body weight (43 d); ADG, average daily gain; ADFI, average daily feed intake; FCR, feed conversion rate; CT, core temperature. ${ }^{a, b}$ Means within the same line with different superscript differ significantly. $(p<0.05)$.

\subsection{Effects of High Temperature on Gastrointestinal Peptide}

The effects of heat stress on the neuropeptides of gut and hypothalamus concentrations in six-week-old chickens were examined and the results are presented in Figures 1-3. Compared with the TC group, GIP concentration in the jejunum of the HT group significantly decreased $(p<0.05)$. The concentration of CCK in the jejunum and serum and ghrelin of the hypothalamus in the HT group was significantly higher than that in the TC group $(p<0.05)$. The GLP-1 in the ileum, PYY in the pancreas, and ghrelin in the jejunum in the HT group were not significantly different from that of the TC group. 


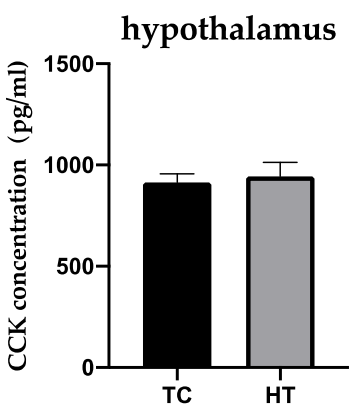

(A)

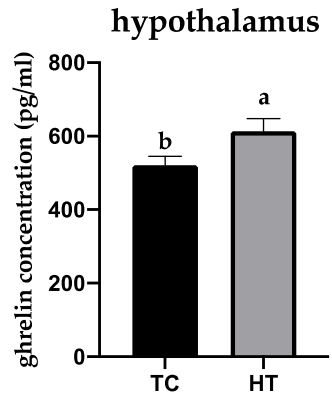

(B)

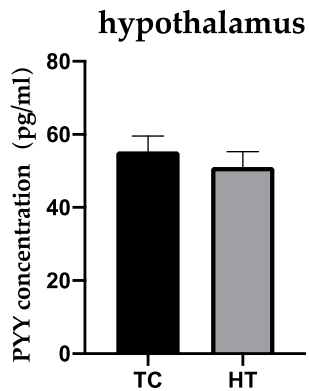

(C)

Figure 1. Effects of high temperatures on CCK, ghrelin, and PYY concentrations in the hypothalamus. (A), cholecystokinin; (B), ghrelin; (C), peptide YY. a,b, Means with different letters within columns indicates significant differences $(p<0.05)$.

jejunum

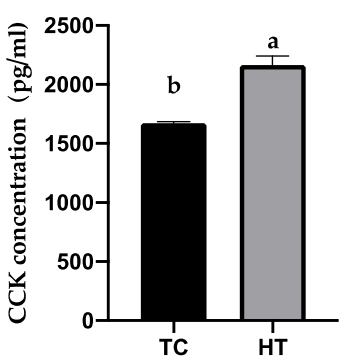

(A)

jejunum

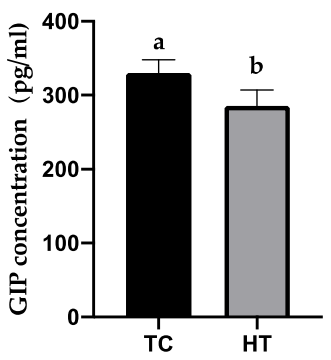

(D) jejunum

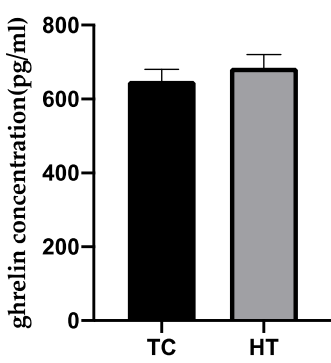

(B)

pancreas

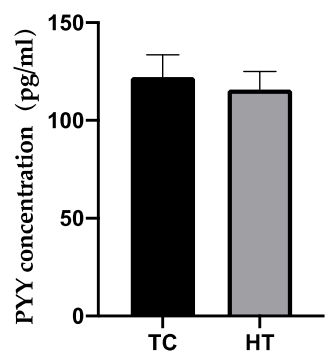

(E)

ileum

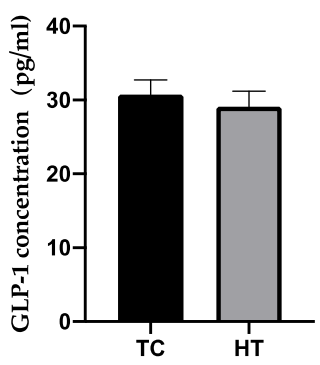

(C)

Figure 2. Effects of high temperature on concentrations of CCK, ghrelin, GIP in jejunum, GLP-1 in ileum and PYY in pancreas. (A), cholecystokinin; (B), ghrelin; (C), glucagon-like peptide-1; (D), glucose-dependent insulinotropic polypeptide; (E), peptide YY. a,b, Means with different letters within columns indicates significant differences $(p<0.05)$. 


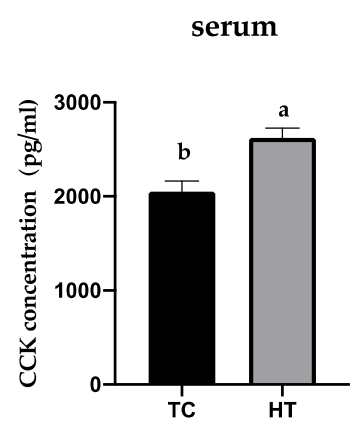

(A)

serum

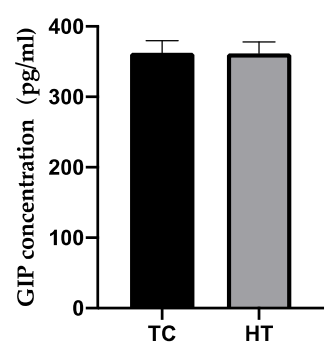

(D) serum

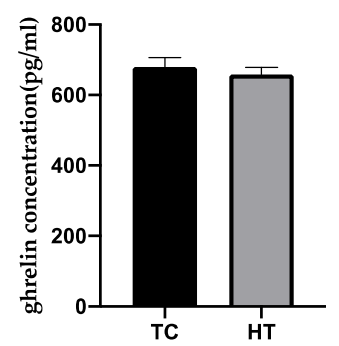

(B)

serum

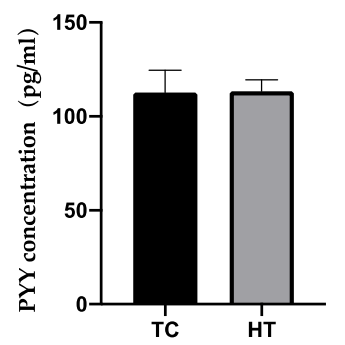

(E) serum

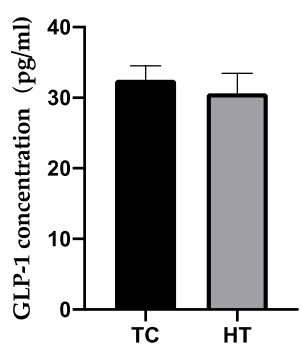

(C)

Figure 3. Effects of high temperature on concentration of CCK, ghrelin, GLP-1, GIP and PYY in serum. (A), cholecystokinin; (B), ghrelin; (C), glucagon-like peptide-1; (D), glucose-dependent insulinotropic polypeptide; (E), peptide YY. a,b Means with different letters within columns indicates significant differences $(p<0.05)$.

\subsection{Effects of High Temperature on Cecal Microbial Composition}

The intestinal microbial community of broilers is mainly concentrated in the cecum; it is the main place where microorganisms participate in the regulation of body metabolism. Therefore, we analyzed the composition of the caecal flora of two groups of broilers at the levels of phylum, family, and genus. The compositions of cecal microbiota at phylum, family, and genus levels are provided in Table 3. At the phylum level, the two groups of flora were mainly composed of Firmicutes, Bacteroides, and Actinomycetes; however, there was no significant difference in abundance. At the family level, the dominant bacteria were mainly Ruminococcaceae; the proportion of Christensenellaceae and Lachnospiraceae decreased significantly, and increased the proportion of Peptostreptococcaceae $(p<0.05)$. It may show that heat stress significantly affects the dominant intestinal flora the family level. At the genus level, the dominant bacteria were mainly Faecalibacterium, Romboutsia. Ruminococcus and Clostridium abundances significantly increased, indicating that the thermal environment significantly increased the proportion of them. 
Table 3. Effects of the thermal environment on cecum digesta microbiota composition.

\begin{tabular}{|c|c|c|c|c|c|}
\hline \multirow{2}{*}{ Level } & \multirow{2}{*}{ Species Name } & \multicolumn{2}{|c|}{ Treatments } & \multirow{2}{*}{ SEM } & \multirow{2}{*}{$p$ Value } \\
\hline & & TC & HT & & \\
\hline & Firmicutes (\%) & 89.33 & 87.49 & 2.18 & $>0.05$ \\
\hline \multirow[t]{2}{*}{ phylum } & Bacteroides (\%) & 5.69 & 5.18 & 0.74 & $>0.05$ \\
\hline & Actinomycetes (\%) & 3.78 & 6.50 & 1.12 & $>0.05$ \\
\hline \multirow{5}{*}{ family } & Ruminococcaceae (\%) & 51.32 & 51.14 & 1.25 & $>0.05$ \\
\hline & Lachnospiraceae (\%) & $18.68^{\mathrm{a}}$ & $10.15^{b}$ & 0.80 & $<0.05$ \\
\hline & Christensenellaceae (\%) & $1.20^{\mathrm{a}}$ & $0.51^{\mathrm{b}}$ & 0.07 & $<0.05$ \\
\hline & Peptococcaceae (\%) & $0.21^{\mathrm{b}}$ & $0.54^{\mathrm{a}}$ & 0.05 & $<0.05$ \\
\hline & Faecalibacterium (\%) & 28.32 & 31.63 & 1.18 & $>0.05$ \\
\hline \multirow{4}{*}{ genus } & Romboutsia (\%) & 6.91 & 11.29 & 0.45 & $>0.05$ \\
\hline & Ruminococcus (\%) & $0.08^{b}$ & $0.15^{\mathrm{a}}$ & 0.02 & $<0.05$ \\
\hline & Clostridium (\%) & $2.55^{b}$ & $5.16^{\mathrm{a}}$ & 0.40 & $<0.05$ \\
\hline & Faecalibacterium $(\%)$ & 28.32 & 31.63 & 1.18 & $>0.05$ \\
\hline
\end{tabular}

Values are means \pm SEM. TC, thermoneutral control group; HT, high temperature group. ${ }^{a, b}$ Means within the same line with different superscript differ significantly $(p<0.05)$.

\subsection{Effects of High Temperature on SCFAs Concentration}

The concentration of short chain fatty acids in cecal contents of the two treatment groups is shown in Table 4. Compared with the TC group, the content of acetate in the HT group significantly increased, but there was no significant difference in propionic acids and butyric acids.

Table 4. Effects of thermal environment on the content of SCFAs in the cecum.

\begin{tabular}{ccccc}
\hline \multirow{2}{*}{ Item } & \multicolumn{2}{c}{ Treatments } & \multirow{2}{*}{ SEM } & \multirow{2}{*}{$p$ Value } \\
\cline { 2 - 3 } & TC & HT & & \\
\hline acetate $(\mu \mathrm{g} / \mathrm{mL})$ & $572.9^{\mathrm{b}}$ & $741.1^{\mathrm{a}}$ & 16.79 & $<0.05$ \\
propionic acids $(\mu \mathrm{g} / \mathrm{mL})$ & 56.45 & 63.96 & 5.89 & $>0.05$ \\
butyric acids $(\mu \mathrm{g} / \mathrm{mL})$ & 262.9 & 252.7 & 29.71 & $>0.05$ \\
\hline
\end{tabular}

Values are means \pm SEM. SCFAs, short chain fatty acids; TC, thermoneutral control group; HT, high temperature group. ${ }^{a, b}$ Means within the same line with different superscript differ significantly. $(p<0.05)$.

\subsection{Effects of High Temperatures on Serum Parameters}

The blood glucose, insulin, insulin resistance index, TG, TC, and NEFA concentrations are shown in Figure 4. Compared with the TC group, the blood glucose and NEFA concentrations in the HT group significantly reduced, the insulin, TC, and TG concentrations significantly increased. Compared with the TC group, the insulin resistance index of broilers under heat stress increased significantly, resulting in severe insulin resistance. 
serum

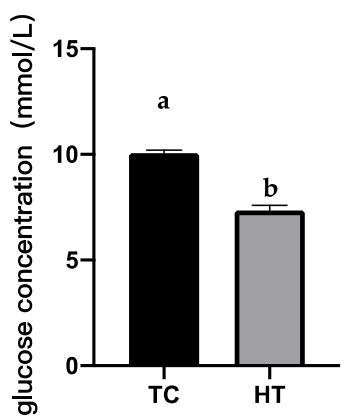

(A)

serum

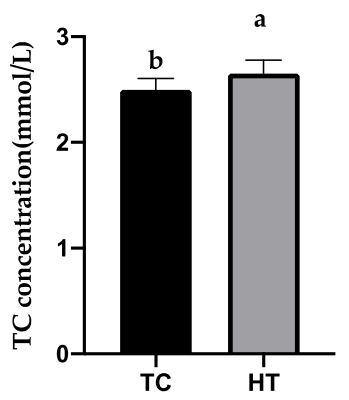

(D) serum

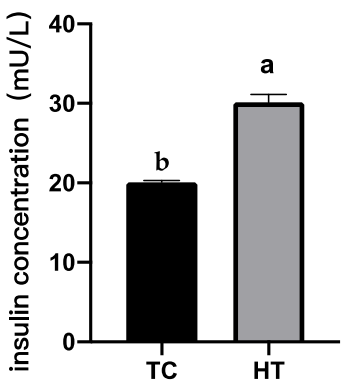

(B)

serum

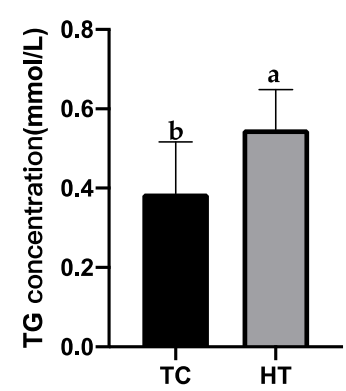

(E) serum

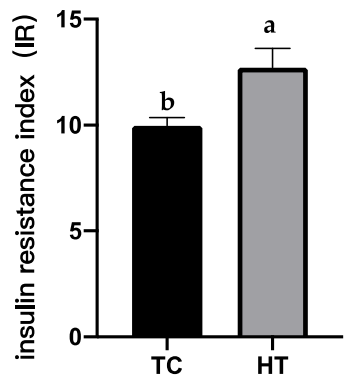

(C)

serum

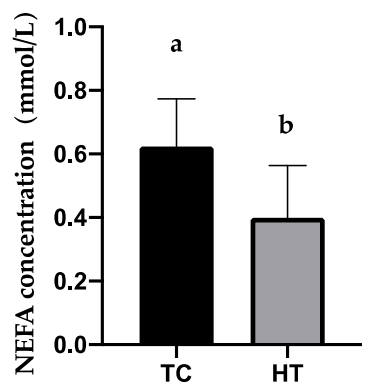

(F)

Figure 4. Effect of high temperature on blood glucose, insulin, insulin resistance index, TC, TG, and NEFA in serum. (A), blood glucose; (B), insulin; (C), insulin resistance index; (D), total cholesterol; (E), triglyceride; (F), non-esterified fatty acid. ${ }^{\mathrm{a}, \mathrm{b}}$ means with different letters within columns indicates significant differences $(p<0.05)$.

\section{Discussion}

Thermal environment severely impairs the performance [28,29], changes the composition of gut microbiota [30], and affects glycolipid metabolism [31] of broilers. However, previous studies have not been able to account for the associations among them. The present study clearly established a significant outcome of a thermal environment on performance, gut microbiota, gastrointestinal peptides, and glycolipid metabolism in broilers, and developed a preliminary understanding of the relationship among them.

Significant elevations were detected in the core temperatures of the birds, meaning that heat stress was produced. Previous literature demonstrated that heat stress could negatively impact ADFI, ADG, and FCR in broilers [2,29,32-34]. The present study showed that ADFI, ADG, and FCR were seriously affected by high temperatures of $31^{\circ} \mathrm{C}$ compared with the $21^{\circ} \mathrm{C}$ group, which agreed with the results of previous studies [2,35]. These results are widely accepted, they imply that heat exposure will directly impair productive performance of birds. In general, the reason for the decline in productive performance is largely due to the lower feed intake; birds reduce feed intake to minimize excess metabolic energy production to keep themselves cool [36]. Another important reason for the weight gain reduction observed in birds experiencing heat stress would be metabolism disorder. Previous studies have shown that thermal environment can disrupt metabolic homeostasis, accelerating protein catabolism [37], increasing abdominal fat deposition [38], changing blood glucose levels, decreasing insulin sensitivity, and causing a negative energy balance [39]. Birds suffering from heat stress may choose to use more energy to resist the damage caused by high temperatures rather than to grow or reproduce. Therefore, the underlying cause of poultry production performance degradation may be metabolic disorder. The current study 
observed that heat stress led to elevated levels of insulin, serum triglycerides, and total cholesterol, and a reduction in serum blood glucose and NEFA. Changes in blood glucose in broilers exposed to high temperatures showed mixed results, as there was evidence for it to increase [3], decrease, or remain unchanged [9]. Numerous factors influence blood glucose and the reasons for the differences include different physiological statuses and experimental designs. The results of elevated levels of insulin [40], serum triglycerides, total cholesterol, and reduced NEFA [41] in this study are consistent with previously reported studies. It is possible that insulin levels were elevated due to compensatory secretions to maintain glucose tolerance. The increased basal insulin levels may explain the lack of an increase in basal NEFA levels because insulin is a potent antilipolytic hormone. We also calculated that the insulin resistance index increased significantly, meaning insulin resistance occurs under heat stress. In summary, these observations imply that heat stress alters carbohydrate and lipid metabolism, leading to metabolic disorder.

Gut microbes have previously been susceptible to heat stress in both mice and livestock. The present study found that heat stress changed the colony composition at the family level, reduced the proportions of Christensenellaceae and Lachnospiraceae, and increased the proportion of Peptococcaceae. It was reported that Christensenellaceae is related to healthy glucose metabolism and reduces the risk of obesity [42]. A previous study reported gut dysbiosis in mice that underwent chronic water avoidance stress; in particular, the abundance of Lachnospiraceae declined [43]. Similar results were obtained in this paper. The increase of Peptococcaceae was mainly related to histopathological infection, indicating that heat stress increased the threat factors of gut health. At the genus level, heat stress increased the proportion of Ruminococcus and Clostridium. In addition, our results showed that heat stress increased the content of acetate in cecal contents. Since Ruminococcus and Clostridium are the main acetate-producing microorganisms, the increase of acetate content in cecal contents may be associated to the increase of Ruminococcus and Clostridium.

Gastrointestinal peptides are mainly secreted by intestinal endocrine cells, including ghrelin, CCK, GIP, PYY, GLP-1, which are directly involved in the regulation of gastrointestinal peristalsis, sensation, and secretion. They have the dual functions of promoting the secretion of neurotransmitters and hormones, and regulating feeding behavior, nutrient absorption, energy metabolism, intestinal peristalsis, and emptying [44]. The results we obtained show that heat stress significantly increased CCK concentration in the jejunum and circulation-similar to the results obtained by a previous study [45]. CCK proved to be an anorexic hormone in various poultry studies, which can gather short-term post-eating satiety signals and inhibit broiler feeding [46]. It was reported that exogenous injection of CCK could significantly reduce the feed intake of poultry [47]. Therefore, the significant decrease in feed intake of broilers in the HT group may be due to the large amount of CCK secreted by the intestines. Several studies have shown that a certain dose of ghrelin is injected into the cerebral ventricle of chicks, and the results are found to strongly inhibit the feed intake of chicks $[48,49]$. In the HT group, a significant increase in hypothalamic ghrelin levels was observed, which is consistent with the results of a previous study [36]. There were no significant changes in other peptides except for ghrelin in the hypothalamus; no significant changes in PYY, ghrelin, and GLP-1 were observed in the intestinal tract and circulation. This is consistent with previous research [50]. It was found that heat stress significantly reduced the plasma GIP concentration of poultry and pigs [51]. The present study found that heat stress significantly reduced the GIP concentration in the jejunum of broilers, and the serum GIP concentration had a decreasing trend. This is supported by previous results. The decreased GIP concentration may be caused by the decreased number of intestinal K cells or the decreased GIP expression in K cells. Another possible explanation for this is that blood glucose was significantly reduced because GIP secretion is glucose-dependent [52].

The gut microbiota participating in host metabolism is frequently reported on [53-55]. According to various studies, such a process is associated with bacterial metabolites, such as SCFAs [56,57]. In the current study, the proportion of acetate-producing bacteria, such 
as Ruminococcus and Clostridium, increased, leading to an increase in acetate production. Studies have found that oral prebiotics may affect the secretion of related gastrointestinal hormones, such as GLP-1 and ghrelin, through the short-chain fatty acids produced by microbiota fermentation [55]. SCFAs have also been shown to cross the blood-brain barrier, directly into the brain, to control feed intake [58]. Furthermore, it was reported that SCFAs can stimulate mouse intestinal L cells to secrete PYY, CCK, and ghrelin, by activating $\mathrm{G}$ protein coupled receptors, such as Gpr41 [59]. A recent study suggested that SCFAs inhibit the secretion of GIP by activating the FFAR3 receptor of $\mathrm{K}$ cells [60]. This evidence implies that the increased CCK and decreased GIP relate to the SCFAs in the current study. Therefore, it is not surprising that the increase in CCK secretion by L cells and the decrease in GIP secretion by K cells may be due to the increased acetate content in the cecal contents.

\section{Conclusions}

This paper argues that the poor production performance of broilers under heat stress may be related to SCFAs fermented by gut microbiota involvement in regulating metabolic disorders. Our data will provide valuable insight for future studies on humans in tropical environments who suffer from metabolic disorders, such as diabetes and obesity.

Author Contributions: Conceptualization, G.W. and M.Z.; methodology, G.W., X.L., and M.Z.; software, G.W.; validation, G.W., X.L., and J.F.; formal analysis, G.W., Y.Z., and X.L.; investigation, G.W., Y.Z., and X.L.; resources, G.W.; data curation, G.W., X.L.; writing-original draft preparation, G.W.; writing-review and editing, G.W., X.L., J.F., and M.Z.; visualization, G.W.; supervision, M.Z.; project administration, J.F.; funding acquisition, M.Z. All authors have read and agreed to the published version of the manuscript.

Funding: This study was supported by the National Key Research and Development Program of China (2016YFD0500509). This research was also supported by the Science and Technology Innovation Project of the Chinese Academy of Agricultural Sciences (ASTIP-IAS09).

Institutional Review Board Statement: The study was conducted according to the guidelines of the Declaration of Helsinki, and approved by the Institutional Ethics Committee of Experiment Animal Welfare and Ethical at the Institute of Animal Science of CAAS (NO:IAS2021-75; 8 April 2021).

Data Availability Statement: Not Applicable.

Conflicts of Interest: The authors declare no conflict of interest.

\section{References}

1. St-Pierre, N.R.; Cobanov, B.; Schnitkey, G. Economic Losses from Heat Stress by US Livestock Industries. J. Dairy Sci. 2003, 86, E52-E77. [CrossRef]

2. Hosseini-Vashan, S.; Golian, A.; Yaghobfar, A.; Zarban, A.; Afzali, N.; Esmaeilinasab, P. Antioxidant Status, Immune System, Blood Metabolites and Carcass Characteristic of Broiler Chickens Fed Turmeric Rhizome Powder under Heat Stress. Afr. J. Biotechnol. 2012, 11, 16118-16125.

3. Garriga, C.; Hunter, R.R.; Amat, C.; Planas, J.M.; Mitchell, M.A.; Moretó, M. Heat Stress Increases Apical Glucose Transport in the Chicken Jejunum. Am. J. Physiol.-Regul. Integr. Comp. Physiol. 2006, 290, R195-R201. [CrossRef] [PubMed]

4. Fan, Y.; Croom, J.; Christensen, V.; Black, B.; Bird, A.; Daniel, L.; Mcbride, B.; Eisen, E. Jejunal Glucose Uptake and Oxygen Consumption in Turkey Poults Selected for Rapid Growth. Poult. Sci. 1997, 76, 1738-1745. [CrossRef] [PubMed]

5. Attia, Y.A.; Al-Harthi, M.A.; Sh Elnaggar, A. Productive, Physiological and Immunological Responses of Two Broiler Strains Fed Different Dietary Regimens and Exposed to Heat Stress. Ital. J. Anim. Sci. 2018, 17, 686-697. [CrossRef]

6. Afsal, A.; Sejian, V.; Madiajagan, B.; Krishnan, G. Heat Stress and Livestock Adaptation: Neuro-Endocrine Regulation. Int. J. Vet. Anim. Med. 2018, 1, 1-8.

7. Xiong, Y.; Yi, H.; Wu, Q.; Jiang, Z.; Wang, L. Effects of Acute Heat Stress on Intestinal Microbiota in Grow-finishing Pigs, and Associations with Feed Intake and Serum Profile. J. Appl. Microbiol. 2020, 128, 840-852. [CrossRef]

8. Akşit, M.; Yalçin, S.; Ozkan, S.; Metin, K.; Ozdemir, D. Effects of Temperature During Rearing and Crating on Stress Parameters and Meat Quality of Broilers. Poult. Sci. 2006, 85, 1867. [CrossRef]

9. Lin, H.; Decuypere, E.; Buyse, J. Acute Heat Stress Induces Oxidative Stress in Broiler Chickens. Comp. Biochem. Physiol. A. Mol. Integr. Physiol. 2006, 144, 11-17. [CrossRef] 
10. Lu, Z.; He, X.F.; Ma, B.B.; Zhang, L.; Li, J.L.; Jiang, Y.; Zhou, G.H.; Gao, F. Increased Fat Synthesis and Limited Apolipoprotein B Cause Lipid Accumulation in the Liver of Broiler Chickens Exposed to Chronic Heat Stress. Poult. Sci. 2019, 98, 3695-3704. [CrossRef]

11. Sands, J.; Smith, M. Effects of Dietary Manganese Proteinate or Chromium Picolinate Supplementation on Plasma Insulin, Glucagon, Glucose and Serum Lipids in Broiler Chickens Reared under Thermoneutral or Heat Stress Conditions. Int. J. Poult. Sci. 2002, 1, 145-149.

12. Geraert, P.A.; Padilha, J.C.F.; Guillaumin, S. Metabolic and Endocrine Changes Induced by Chronic Heatexposure in Broiler Chickens: Growth Performance, Body Composition and Energy Retention. Br. J. Nutr. 1996, 75, 195-204. [CrossRef] [PubMed]

13. Song, J.; Xiao, K.; Ke, Y.L.; Jiao, L.F.; Hu, C.H.; Diao, Q.Y.; Shi, B.; Zou, X.T. Effect of a Probiotic Mixture on Intestinal Microflora, Morphology, and Barrier Integrity of Broilers Subjected to Heat Stress. Poult. Sci. 2014, 93, 581-588. [CrossRef]

14. Park, S.-O.; Hwangbo, J.; Ryu, C.-M.; Park, B.-S.; Chae, H.-S.; Choi, H.-C.; Seo, O.-S.; Choi, Y.-H. Effects of Extreme Heat Stress on Growth Performance, Lymphoid Organ, IgG and Cecum Microflora of Broiler Chickens. Int. J. Agric. Biol. 2013, 15, 5.

15. Ramiah, S.K.; Atta Awad, E.; Hemly, N.I.M.; Ebrahimi, M.; Joshua, O.; Jamshed, M.; Saminathan, M.; Soleimani, A.F.; Idrus, Z. Effects of Zinc Oxide Nanoparticles on Regulatory Appetite and Heat Stress Protein Genes in Broiler Chickens Subjected to Heat Stress. J. Anim. Sci. 2020, 98, skaa300. [CrossRef]

16. Tremaroli, V.; Bäckhed, F. Functional Interactions between the Gut Microbiota and Host Metabolism. Nature 2012, 489, 242-249. [CrossRef]

17. Ducray, H.A.G.; Globa, L.; Pustovyy, O.; Morrison, E.; Vodyanoy, V.; Sorokulova, I. Yeast Fermentate Prebiotic Improves Intestinal Barrier Integrity during Heat Stress by Modulation of the Gut Microbiota in Rats. J. Appl. Microbiol. 2019, 127, $1192-1206$. [CrossRef]

18. Giles, K.; Pluvinage, B.; Boraston, A.B. Structure of a Glycoside Hydrolase Family 50 Enzyme from a Subfamily That Is Enriched in Human Gut Microbiome Bacteroidetes: Structure of a Bacteroides GH50. Proteins Struct. Funct. Bioinform. 2017, 85, 182-187. [CrossRef]

19. Cani, P.D.; Dewever, C.; Delzenne, N.M. Inulin-Type Fructans Modulate Gastrointestinal Peptides Involved in Appetite Regulation (Glucagon-like Peptide-1 and Ghrelin) in Rats. Br. J. Nutr. 2004, 92, 521-526. [CrossRef]

20. Baggio, L.L.; Drucker, D.J. Biology of Incretins: GLP-1 and GIP. Gastroenterology 2007, 132, 2131-2157. [CrossRef]

21. Højlund, K. Metabolism and Insulin Signaling in Common Metabolic Disorders and Inherited Insulin Resistance. Dan. Med. J. 2014, 61, B4890. [PubMed]

22. Chen, S.; Zhou, Y.; Chen, Y.; Gu, J. Fastp: An Ultra-Fast All-in-One FASTQ Preprocessor. Bioinformatics 2018, 34, i884-i890. [CrossRef]

23. Magoc, T.; Salzberg, S.L. FLASH: Fast Length Adjustment of Short Reads to Improve Genome Assemblies. Bioinformatics 2011, 27, 2957-2963. [CrossRef] [PubMed]

24. Edgar, R.C. UPARSE: Highly Accurate OTU Sequences from Microbial Amplicon Reads. Nat. Methods 2013, 10, 996-998. [CrossRef] [PubMed]

25. Stackebrandt, E.; Goebel, B.M. Taxonomic Note: A Place for DNA-DNA Reassociation and 16S RRNA Sequence Analysis in the Present Species Definition in Bacteriology. Int. J. Syst. Evol. Microbiol. 1994, 44, 846-849. [CrossRef]

26. Wang, Q.; Garrity, G.M.; Tiedje, J.M.; Cole, J.R. Naïve Bayesian Classifier for Rapid Assignment of RRNA Sequences into the New Bacterial Taxonomy. Appl. Environ. Microbiol. 2007, 73, 5261-5267. [CrossRef] [PubMed]

27. Matthews, D.R.; Hosker, J.P.; Rudenski, A.S.; Naylor, B.A.; Treacher, D.F.; Turner, R.C. Homeostasis Model Assessment: Insulin Resistance and Beta-Cell Function from Fasting Plasma Glucose and Insulin Concentrations in Man. Diabetologia 1985, $28,412$. [CrossRef]

28. Bartlett, J.R.; Smith, M.O. Effects of Different Levels of Zinc on the Performance and Immunocompetence of Broilers Under Heat Stress. Poult. Sci. 2003, 82, 1580-1588. [CrossRef]

29. Niu, Z.Y.; Liu, F.Z.; Yan, Q.L.; Li, W.C. Effects of Different Levels of Vitamin E on Growth Performance and Immune Responses of Broilers under Heat Stress. Poult. Sci. 2009, 88, 2101-2107. [CrossRef]

30. Shi, D.; Bai, L.; Qu, Q.; Zhou, S.; Yang, M.; Guo, S.; Li, Q.; Liu, C. Impact of Gut Microbiota Structure in Heat-Stressed Broilers. Poult. Sci. 2019, 98, 2405-2413. [CrossRef]

31. Lu, Z.; He, X.; Ma, B.; Zhang, L.; Li, J.; Jiang, Y.; Zhou, G.; Gao, F. Chronic Heat Stress Impairs the Quality of Breast-Muscle Meat in Broilers by Affecting Redox Status and Energy-Substance Metabolism. J. Agric. Food Chem. 2017, 65, 11251-11258. [CrossRef] [PubMed]

32. Mujahid, A.; Yoshiki, Y.; Akiba, Y.; Toyomizu, M. Superoxide Radical Production in Chicken Skeletal Muscle Induced by Acute Heat Stress. Poult. Sci. 2005, 84, 307-314. [CrossRef] [PubMed]

33. Quinteiro-Filho, W.M.; Ribeiro, A.; Ferraz-De-Paula, V.; Pinheiro, M.L.; Sakai, M.; Sa, L.; Ferreira, A.; Palermo-Neto, J. Heat Stress Impairs Performance Parameters, Induces Intestinal Injury, and Decreases Macrophage Activity in Broiler Chickens. Poult. Sci. 2010, 89, 1905-1914. [CrossRef] [PubMed]

34. Zeferino, C.P.; Komiyama, C.M.; Pelícia, V.C.; Fascina, V.B.; Aoyagi, M.M.; Coutinho, L.L.; Sartori, J.R.; Moura, A.S.A.M.T. Carcass and Meat Quality Traits of Chickens Fed Diets Concurrently Supplemented with Vitamins C and E under Constant Heat Stress. Animal 2016, 10, 163-171. [CrossRef] [PubMed] 
35. Han, G.; Yang, H.; Wang, Y.; Haraguchi, S.; Miyazaki, T.; Bungo, T.; Tashiro, K.; Furuse, M.; Chowdhury, V.S. L-Leucine Increases the Daily Body Temperature and Affords Thermotolerance in Broiler Chicks. Asian-Australas. J. Anim. Sci. 2019, 32, 842-848. [CrossRef] [PubMed]

36. Song, Z.; Liu, L.; Sheikhahmadi, A.; Jiao, H.; Lin, H. Effect of Heat Exposure on Gene Expression of Feed Intake Regulatory Peptides in Laying Hens. J. Biomed. Biotechnol. 2012, 2012, 1-8. [CrossRef]

37. Yunianto, V.D.; Hayashit, K.; Kaiwda, S.; Ohtsuka, A.; Tomita, Y. Effect of Environmental Temperature on Muscle Protein Turnover and Heat Production in Tube-Fed Broiler Chickens. Br. J. Nutr. 1997, 77, 897-909. [CrossRef]

38. Lu, Q.; Wen, J.; Zhang, H. Effect of Chronic Heat Exposure on Fat Deposition and Meat Quality in Two Genetic Types of Chicken. Poult. Sci. 2007, 86, 1059-1064. [CrossRef]

39. Toghyani, M.; Toghyani, M.; Shivazad, M.; Gheisari, A.; Bahadoran, R. Chromium Supplementation Can Alleviate the Negative Effects of Heat Stress on Growth Performance, Carcass Traits, and Meat Lipid Oxidation of Broiler Chicks without Any Adverse Impacts on Blood Constituents. Biol. Trace Elem. Res. 2012, 146, 171-180. [CrossRef]

40. Yuan, L.; Lin, H.; Jiang, K.J.; Jiao, H.C.; Song, Z.G. Corticosterone Administration and High-Energy Feed Results in Enhanced Fat Accumulation and Insulin Resistance in Broiler Chickens. Br. Poult. Sci. 2008, 49, 487-495. [CrossRef]

41. Lu, Z.; He, X.; Ma, B.; Zhang, L.; Li, J.; Jiang, Y.; Zhou, G.; Gao, F. Serum Metabolomics Study of Nutrient Metabolic Variations in Chronic Heat-Stressed Broilers. Br. J. Nutr. 2018, 119, 771-781. [CrossRef]

42. Goodrich, J.K.; Waters, J.L.; Poole, A.C.; Sutter, J.L.; Koren, O.; Blekhman, R.; Beaumont, M.; Van Treuren, W.; Knight, R.; Bell, J.T.; et al. Human Genetics Shape the Gut Microbiome. Cell 2014, 159, 789-799. [CrossRef]

43. Zhang, J.; Song, L.; Wang, Y.; Liu, C.; Zhang, L.; Zhu, S.; Liu, S.; Duan, L. Beneficial Effect of Butyrate-producing Lachnospiraceae on Stress-induced Visceral Hypersensitivity in Rats. J. Gastroenterol. Hepatol. 2019, 34, 1368-1376. [CrossRef]

44. Demidova, T.Y.; Lobanova, K.G.; Oynotkinova, O.S. Gut Microbiota Is an Endocrine Organ. Obes. Metab. 2020, 17, 299-306. [CrossRef]

45. He, X.; Lu, Z.; Ma, B.; Zhang, L.; Li, J.; Jiang, Y.; Zhou, G.; Gao, F. Chronic Heat Stress Alters Hypothalamus Integrity, the Serum Indexes and Attenuates Expressions of Hypothalamic Appetite Genes in Broilers. J. Therm. Biol. 2019, 81, 110-117. [CrossRef]

46. Melo-Duran, D.; Gonzalez-Ortiz, G.; Sola-Oriol, D.; Martinez-Mora, M.; Perez, J.F.; Bedford, M.R. Relationship between Peptide YY, Cholecystokinin and Fermentation Products in Fasted, Re-Fed and Ad Libitum Fed Broiler Chickens. Anim. Feed Sci. Technol. 2019, 247, 141-148. [CrossRef]

47. Louie, D.S.; May, D.; Miller, P.; Owyang, C. Cholecystokinin Mediates Feedback Regulation of Pancreatic Enzyme Secretion in Rats. Am. J. Physiol. Gastrointest. Liver Physiol. 1986, 250, G252-G259. [CrossRef] [PubMed]

48. Furuse, M.; Tachibana, T.; Ohgushi, A.; Ando, R.; Yoshimatsu, T.; Denbow, D.M. Intracerebroventricular Injection of Ghrelin and Growth Hormone Releasing Factor Inhibits Food Intake in Neonatal Chicks. Neurosci. Lett. 2001, 301, 123-126. [CrossRef]

49. Xu, P.; Siegel, P.B.; Denbow, D.M. Genetic Selection for Body Weight in Chickens Has Altered Responses of the Brain's AMPK System to Food Intake Regulation Effect of Ghrelin, but Not Obestatin. Behav. Brain Res. 2011, 221, 216-226. [CrossRef]

50. Liu, L.; Song, Z.; Jiao, H.; Lin, H. Glucocorticoids Increase NPY Gene Expression via Hypothalamic AMPK Signaling in Broiler Chicks. Endocrinology 2014, 155, 2190-2198. [CrossRef] [PubMed]

51. Pearce, S. Evaluation of the Chronological Impact Heat Stress Has on Swine Intestinal Function and Integrity. Ph.D. Thesis, Iowa State University, Ames, IA, USA, 2014.

52. Ding, K.-H.; Shi, X.-M.; Zhong, Q.; Kang, B.; Xie, D.; Bollag, W.B.; Bollag, R.J.; Hill, W.; Washington, W.; Mi, Q.-S.; et al. Impact of Glucose-Dependent Insulinotropic Peptide on Age-Induced Bone Loss. J. Bone Miner. Res. 2007, 23, 536-543. [CrossRef] [PubMed]

53. Flint, H.J.; Duncan, S.H.; Scott, K.P.; Louis, P. Links between Diet, Gut Microbiota Composition and Gut Metabolism. Proc. Nutr. Soc. 2015, 74, 13-22. [CrossRef] [PubMed]

54. Holmes, E.; Li, J.V.; Marchesi, J.R.; Nicholson, J.K. Gut Microbiota Composition and Activity in Relation to Host Metabolic Phenotype and Disease Risk. Cell Metab. 2012, 16, 559-564. [CrossRef]

55. Cani, P.D.; Lecourt, E.; Dewulf, E.M.; Sohet, F.M.; Pachikian, B.D.; Naslain, D.; De Backer, F.; Neyrinck, A.M.; Delzenne, N.M. Gut Microbiota Fermentation of Prebiotics Increases Satietogenic and Incretin Gut Peptide Production with Consequences for Appetite Sensation and Glucose Response after a Meal. Am. J. Clin. Nutr. 2009, 90, 1236-1243. [CrossRef]

56. den Besten, G.; Bleeker, A.; Gerding, A.; van Eunen, K.; Havinga, R.; van Dijk, T.H.; Oosterveer, M.H.; Jonker, J.W.; Groen, A.K.; Reijngoud, D.-J.; et al. Short-Chain Fatty Acids Protect Against High-Fat Diet-Induced Obesity via a PPAR $\gamma$-Dependent Switch From Lipogenesis to Fat Oxidation. Diabetes 2015, 64, 2398-2408. [CrossRef]

57. Chambers, E.S.; Viardot, A.; Psichas, A.; Morrison, D.J.; Murphy, K.G.; Zac-Varghese, S.E.K.; MacDougall, K.; Preston, T.; Tedford, C.; Finlayson, G.S.; et al. Effects of Targeted Delivery of Propionate to the Human Colon on Appetite Regulation, Body Weight Maintenance and Adiposity in Overweight Adults. Gut 2015, 64, 1744-1754. [CrossRef]

58. Klosterbuer, A.; Sanders, L.; Potter, S.; Thomas, W.; Slavin, J. A Blend of Soluble Fiber and Resistant Starch Promotes Feelings of Fullness in Humans. FASEB J. 2010, 24, 220-224.

59. Samuel, B.S.; Shaito, A.; Motoike, T.; Rey, F.E.; Backhed, F.; Manchester, J.K.; Hammer, R.E.; Williams, S.C.; Crowley, J.; Yanagisawa, M.; et al. Effects of the Gut Microbiota on Host Adiposity Are Modulated by the Short-Chain Fatty-Acid Binding G ProteinCoupled Receptor, Gpr41. Proc. Natl. Acad. Sci. USA 2008, 105, 16767-16772. [CrossRef]

60. Lee, E.-Y.; Zhang, X.; Miyamoto, J.; Kimura, I.; Taknaka, T.; Furusawa, K.; Jomori, T.; Fujimoto, K.; Uematsu, S.; Miki, T. Gut Carbohydrate Inhibits GIP Secretion via a Microbiota/SCFA/FFAR3 Pathway. J. Endocrinol. 2018, 239, 267-276. [CrossRef] 